\title{
Salinity Interchange between Salt Water in Sand and Overflowing Fresh Water at Low Tide. II.
}

\author{
By \\ D. M. Reid, \\ Department of Biology, Harrow School.
}

With 4 Figures in the Text.

THE following is a continuation of the work described in a previous paper (Reid, 1930). The intention was to amplify that work by the investigation of the conditions of salinity interchange on sandy shores of less ideal type. It was considered likely that various factors might affect the condition of the water held by the sand. For instance, the rate of flow of the fresh water and its depth; irregularity in the slope of the beach; the depth of the sand and the nature of the floor on which it rests. The rate of flow of the water is not a simple factor however. It is correlated with the slope of the beach in that faster streams are usually on steeper beaches. The effect of this dual factor will be discussed later.

In the previous paper the depth of the sand appeared to be considerable, at least it was sufficiently deep not to interfere with the sampling. In the present case some of the beaches were composed of a very shallow layer of sand resting on a bed of shingle or solid rock. In one case there was a good deal of shingle mixed with the sand. With so many factors to deal with it is somewhat difficult to assign to each its particular effect.

\section{Methods.}

Sampling was carried out as already described in the previous paper. The samples were titrated with $\mathrm{AgNO}_{3}$ standardised against Normal Sea-water. No attempt was made to estimate the $\mathrm{pH}$.

\section{Whitesand Bay (St. David's), PembBoke.}

The sets of readings taken in this bay are very much more numerous than in the other instances - the object being to study at each point the changes in salinity that take place at successive intervals of time after the sand has been uncovered by the tide and to study the variation with tidal conditions. 
To avoid inaccuracies in sampling, at each station from H.W.M. a number of samples were collected in a line across the stream parallel to H.W.M., and these samples were combined for analysis.

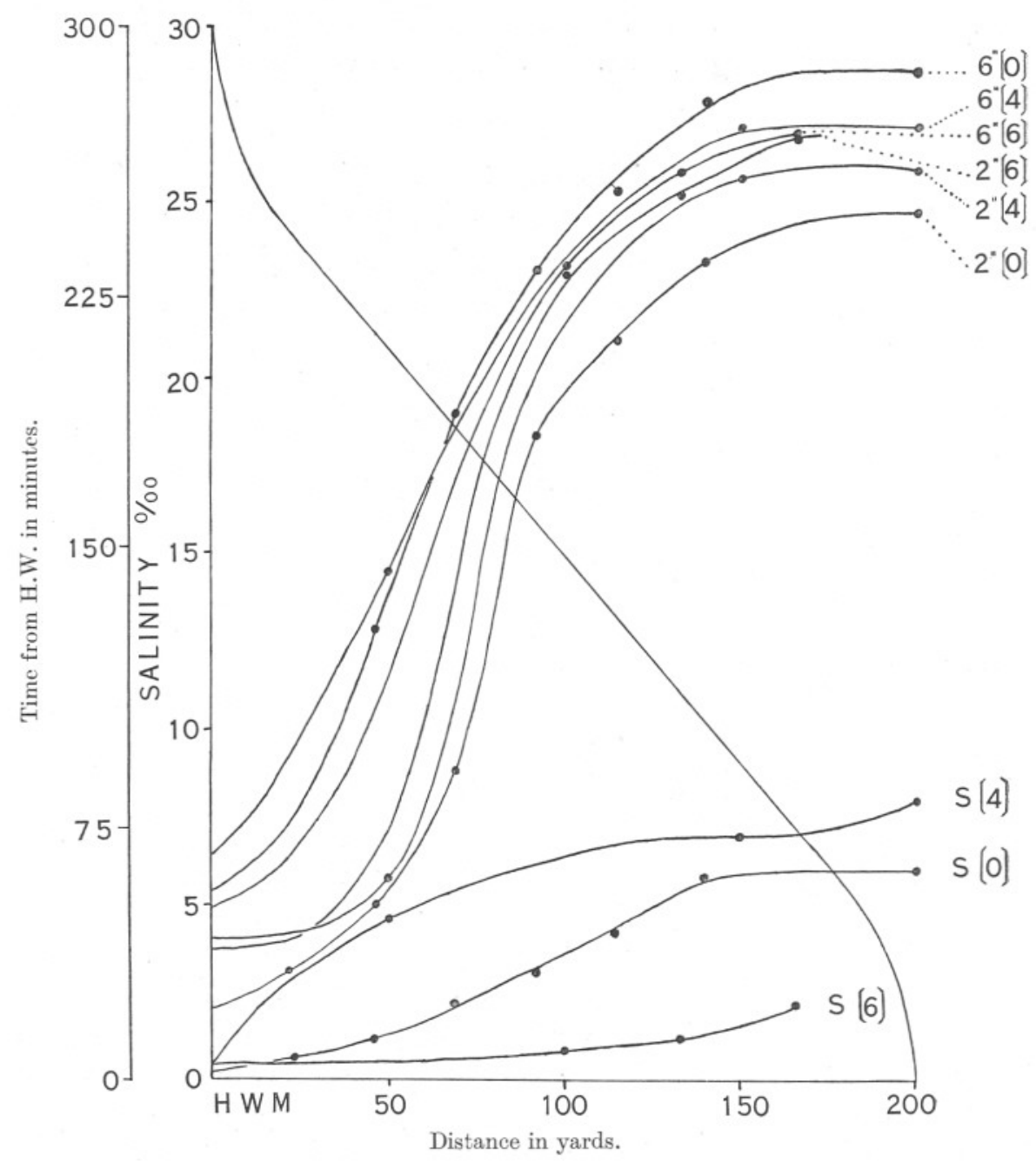

Fig. 1.-Whitesand Bay (St. David's). $\mathrm{S}(\mathrm{O})=\mathrm{S} \%$ of surface water just after the tide had uncovered that point. $2^{\prime \prime}(6)$, etc. $=\mathrm{S} \%$ o at that depth $6 \mathrm{hrs}$. after the tide had uncovered that point.

Besides this, an investigation of the variation of salinity of the water in the sand with the state of the tide was made by spacing out the intervals of sampling so that they fell, as nearly as could be arranged for the work, on the dates of Spring, Neap, and Intermediate Tides. The points on the 
various curves (Fig. 1) represent the results of analyses of all samples taken on various days (under the particular conditions of time and depth stated on the curve), and the fact that they lie on a smooth curve, although readings were taken on different days when different tidal conditions obtained, show that if the distances be measured from H.W.M. of the day in question the tidal conditions do not affect the salinity interchange.

As in the case quoted in the previous paper, the sand in this bay is fairly homogeneous down to a depth of at least 12 inches when pebbles

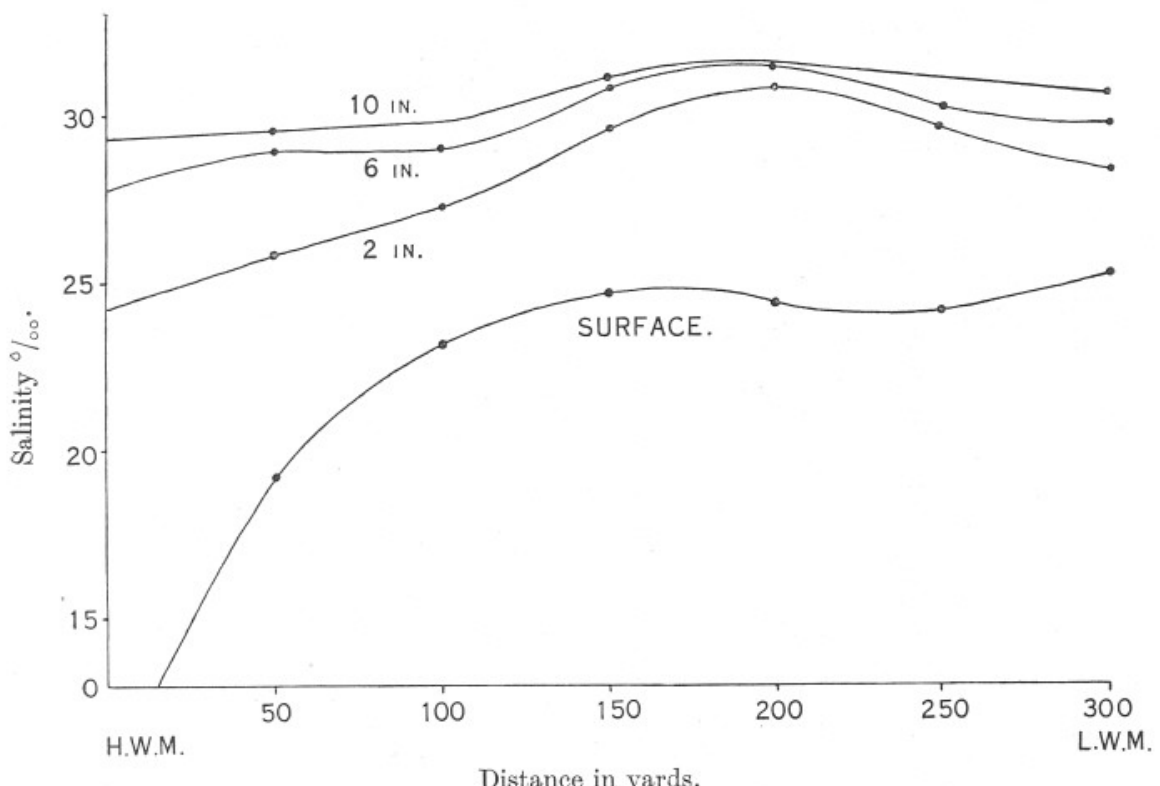

Fra. 2.-Bude River.

begin to be sufficiently numerous to make sampling uncertain. These pebbles, however, are far enough below the surface to have little, if any, effect on the problem.

The Whitesand Bay conditions closely resemble those previously described with the important exception that here the slope, though regular, is steeper. As a consequence of this the overflowing water travels at a greater pace and there is a mechanical draining out of salt water from the sand which will account for the absence of that flattening out of the curves which is so marked in the previous case. Despite this absence of a flattened area there is a marked tendency of the part of the curves to maintain a kind of equilibrium at the place where they are crossed by the simple 
harmonic curve of the rate of tidal rise and fall. The harmonic curve was drawn in accordance with the formula

$\mathrm{h}=\frac{1}{2} \mathrm{r} \operatorname{Cos} \theta$ where $\mathrm{h}=$ height of tide above mean tide level. $\mathrm{r}=$ range of tide.

$$
\theta \text { is an angle }=\frac{\text { Interval from H. or L.W. }}{\text { Duration of rise or fall. }} \times 180^{\circ} .
$$

\section{Whitesand Bay (St. David's).}

TABLE OF SALINITY READINGS.

Dates 26 and $30 / 8 / 31$ and $7 / 9 / 31$. Tidal Data.

Maximum Tidal Range $22 \cdot 7 \mathrm{ft}$.
Weather settled and calm. Depth of Flowing Water 1-6 in. Speed of Flowing Water 3-4 ft. p. sec. Distances from H.W.M. (yd.).

$\begin{array}{lllllllllllllll}\text { SALINITIES } \% & 0 & 23 & 46 & 50 & 69 & 92 & 100 & 115 & 133 & 140 & 150 & 166 & 200 & 240\end{array}$

Tide just off.

$\begin{array}{llll}\text { Surface } & 0 \cdot 2 & 0 \cdot 6 & 1 \cdot 1\end{array}$

2 in. $\quad 2.0 \quad 2 \cdot 8 \quad 5 \cdot 0$

$2 \cdot 1 \quad 3 \cdot 0$

$8 \cdot 8 \quad 18 \cdot 4$

\section{$4 \cdot 1$}

$5 \cdot 8$

$23 \cdot 4$ $\begin{array}{ll}19 \cdot 0 & 23 \cdot 1\end{array}$

$25 \cdot 3$

$28 \cdot 0$ $5 \cdot 4$

Tide 4 hr. off.

$\begin{array}{llr}\text { Surface } & 0 \cdot 4 & 4 \cdot 6 \\ 2 \text { in. } & 4 \cdot 0 & 5 \cdot 7 \\ 6 \text { in } & 6 \cdot 4 & 14 \cdot 4\end{array}$

6 in. $\quad 6 \cdot 4 \quad 14 \cdot 4$

$5 \cdot 7$
$14 \cdot 4$

Tide 6 hr. off.

Surface $\quad 0.4$

2 in. $\quad 3 \cdot 7$

6 in. $\quad 4 \cdot 9$

$\begin{array}{rr}0 \cdot 8 & 1 \cdot 1 \\ 23 \cdot 0 & 25 \cdot 2 \\ 23 \cdot 1 & 25 \cdot 9\end{array}$

$2 \cdot 1$

$26 \cdot 8$

$26 \cdot 8$

Tide $11 \mathrm{hr}$. off.

$\begin{array}{ll}\text { Surface } & 0 \cdot 2 \\ 2 \text { in. } & 0 \cdot 4 \\ 6 \text { in. } & 2 \cdot 3\end{array}$

\section{Bude River, Cornwall.}

This river differs from the others in that it flows over the sand in a welldefined channel for a large part of its course. It is comparatively deep (12 inches) and has a speed of about $3 \mathrm{ft}$. per sec.

It is, however, the bed on which the sand rests which is of greatest interest. The sand layer is fairly shallow, being little more than 10 inches deep at the points where the samples were taken. Below the sand there is a rock floor formed by the trough of the syncline whose sides form the lateral boundaries of the bay and whose axis lies at right angles to the tide marks. The general slope of the beach is fairly regular and so would tend to make the conditions fairly normal were it not for the fact that the stream does not flow directly from H.W. to L.W.M. in a straight line but cuts across the beach diagonally until, at about $180 \mathrm{yd}$., it comes close to the uprising side of the anticline. At this point, then, there is what amounts to a rock wall having against it a rampart of sand which, in turn, acts as a 
salt reservoir for the sand below the stream and thus accounts for the sudden increase in salinity at this point (see Fig. 3).

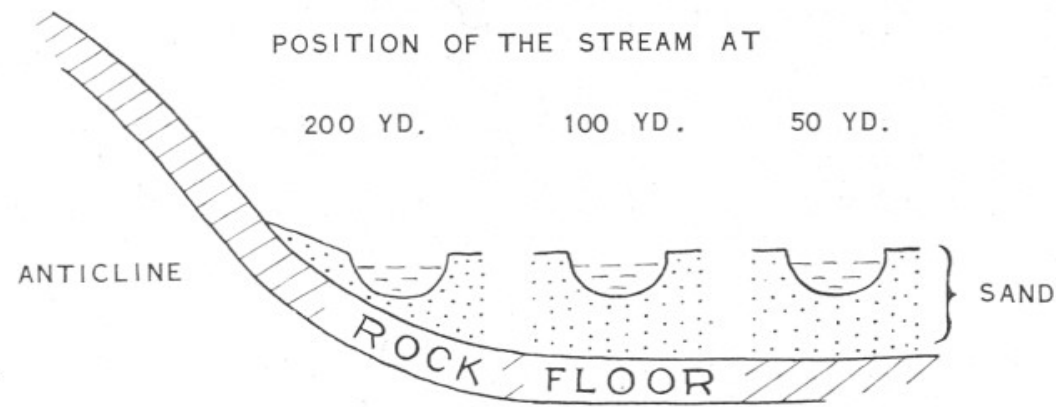

Fig. 3.-Diagrammatic section through part of Bude Bay.

\section{Bude River (Bude Bay).}

TABLE OF READINGS.

Date $11 / 9 / 29$.

Tidal Data.

Ht. of High Tide $11 / 9 / 29$

Max. ht. Spring Tide

Ht. of Low Tide 11/9/29

Average Tidal Range
Weather, Fine.

$21 \cdot 2 \mathrm{ft}$.

$23 \cdot 9 \mathrm{ft}$.

$3 \cdot 1 \mathrm{ft}$.

$18.5 \mathrm{ft}$.
Wind, 0 .

Time $\quad 3-4$ p.m.

Temp. $\quad$ Air $20^{\circ} \mathrm{C}$, Water $19^{\circ} \mathrm{C}$.

Depth of Flowing Water 3-8 in.

Speed of Flowing Water $2-3 \mathrm{ft}$. p. sec. $\mathrm{S} \%$ at 10 inches in the Sand.

Station.

H.W.M.

$50 \mathrm{yd}$.

$100 \mathrm{yd}$.

$150 \mathrm{yd}$.

200 yd.

$250 \mathrm{yd}$.

$300 \mathrm{yd}$.

below H.W.M.

$\begin{array}{cc}\text { S\% of } & \text { S\% at } \\ \text { Surface Water. } & 2 \text { inches. } \\ 8 \cdot 3 & 24 \cdot 3 \\ 10 \cdot 2 & 25 \cdot 9 \\ 23 \cdot 2 & 27 \cdot 3 \\ 24 \cdot 7 & 29 \cdot 6 \\ 24 \cdot 4 & 30 \cdot 8 \\ 24 \cdot 2 & 29 \cdot 6 \\ 25 \cdot 3 & 28 \cdot 4\end{array}$

$\mathrm{S} \%$ at
6 inches.
$27 \cdot 8$
$28 \cdot 9$
$29 \cdot 0$
$30 \cdot 8$
$31 \cdot 4$
$30 \cdot 2$
$29 \cdot 8$

$29 \cdot 3$

$29 \cdot 5$

$31 \cdot 1$

$30 \cdot 6$

Beyond the 200 yd. point (see Fig. 2) the drop in salinity seems to be accounted for by the fact that the channel becomes less well defined and steeper, so that more rapid interchange takes place between the water in the sand and the overflowing water.

It seems probable that the even concentration gradient with depth is due to the well-defined channel and the rock floor acting as an impervious layer. Thus the salt water withdrawn will tend to be replaced more rapidly and evenly by the salt water from the surrounding sand than it would be were the sand of greater depth or not resting on an impervious bed. 


\section{Rej River (St. Ives Bay), Cornwall.}

At first sight the investigations in this locality appear to show conditions so variable as to be of little interest or value. The slope of the beach and the depth, speed, and course of the overflowing fresh water vary irregularly from station to station. The maximum depth to which the sampler could be driven through the sand was 12 inches. At that depth it came into contact with a layer of shingle which underlies the sand and crops out

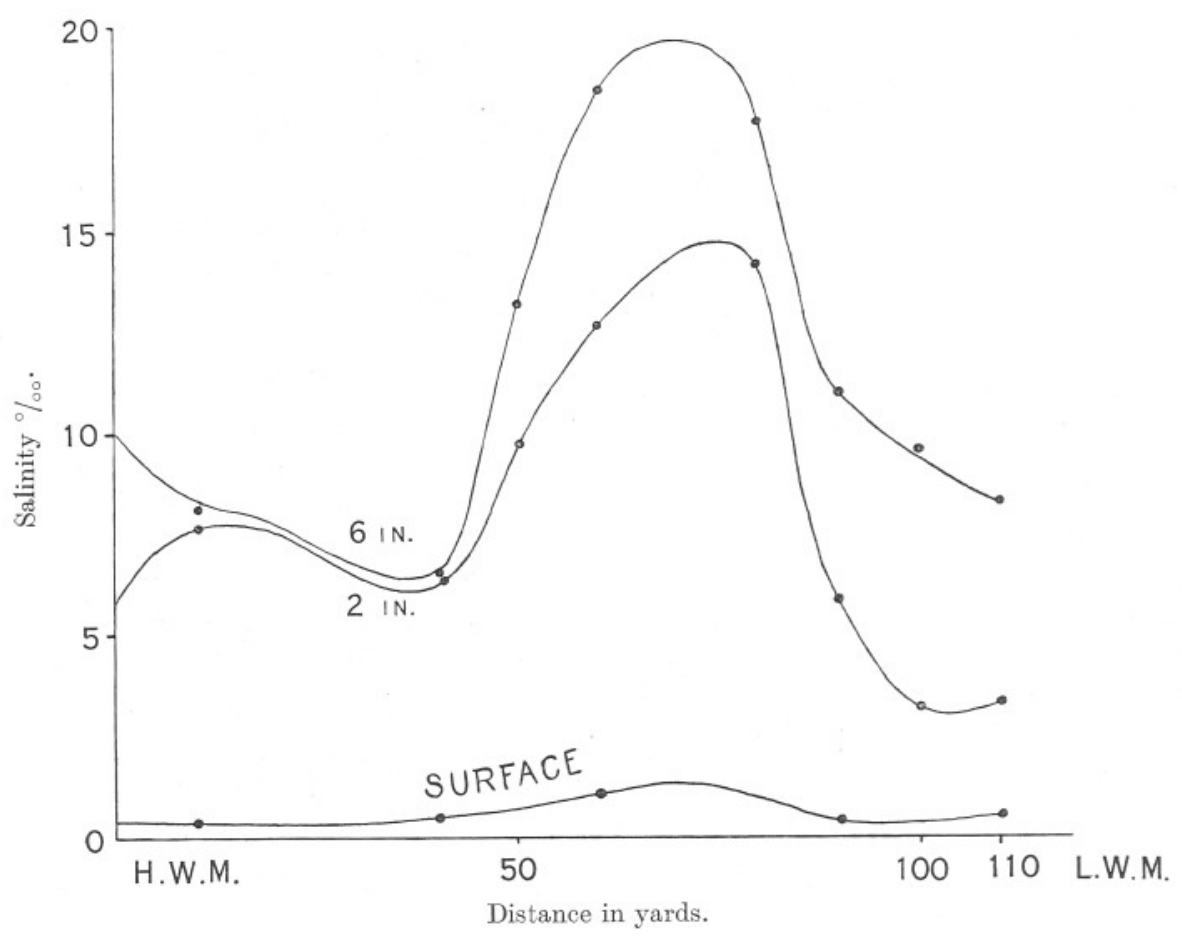

FIg. 4.-Red River (St. Ives Bay).

near H.W.M. The overflowing water at no time shows any real increase in salinity (see Fig. 4). Where the sand and pebbles are fairly evenly mixed (i.e. for the first $40 \mathrm{yd}$. from H.W.M.) a rapid fall in the salinity of the water in the sand is indicated and is probably due to its quick removal by the overflowing water as soon as the tide has receded. In the next part, from 50-80 yd., the great increase in the salinity of the water in the sand is due to a very disturbing condition but one that is probably common to a good many beaches. This is a well-defined layer of pebbles below the sand. Such a layer of pebbles will provide an under- 
ground channel for the fresh water and prevent it from coming into contact with the overlying sand and its contained water so that practically no salinity interchange takes place.

Beyond the $80 \mathrm{yd}$. point the rapid fall in the salinity of the water in the sand is explained by the emission of the water from the underground channel; in fact, the conditions are similar to those found in the first $40 \mathrm{yd}$.

In general it may be stated that, since the stream flows through this open shingle-sand mixture it very soon removes the bulk of the available salt after the tide has receded and thereafter there is no more salt to remove.

\section{Red River (St. Ives Bay).}

TABLE OF READINGS.

Date $9 / 9 / 30$.

Tidal Data.

Ht. of High Tide $9 / 9 / 30$

Max. ht. Spring Tide

Ht. of Low Tide 9/9/30

Average Tidal Range

\section{Stations.}

H.W.M.

10 yd. below H.W.

40 yd. below H.W.

50 yd. below H.W.

60 yd. below H.W.

80 yd. below H.W.

90 yd. below H.W.

100 yd. below H.W.

110 yd. below H.W.

Weather, Fine.

Wind, 0 .

$15.6 \mathrm{ft}$.
$24 \cdot 1 \mathrm{ft}$.
$5.4 \mathrm{ft}$.
$12 \cdot 6 \mathrm{ft}$.

\begin{tabular}{c|c|c|}
$\begin{array}{c}\mathrm{S} \% \text { of } \\
\text { Surface Water. }\end{array}$ & $\begin{array}{c}\mathrm{S} \% \text { at } \\
2 \text { inches. }\end{array}$ & $\begin{array}{c}\mathrm{S} \% \text { at } \\
6 \text { inches. }\end{array}$ \\
\hline $0 \cdot 46$ & $5 \cdot 78$ & $10 \cdot 0$ \\
$0 \cdot 34$ & $7 \cdot 9$ & $8 \cdot 02$ \\
$0 \cdot 46$ & $6 \cdot 24$ & $6 \cdot 31$ \\
& $9 \cdot 73$ & $13 \cdot 1$ \\
1.03 & $12 \cdot 6$ & $18 \cdot 4$ \\
& $14 \cdot 1$ & $17 \cdot 5$ \\
$0 \cdot 34$ & $5 \cdot 84$ & $10 \cdot 9$ \\
0.25 & $3 \cdot 15$ & $9 \cdot 56$ \\
0.57 & 3.32 & 8.24
\end{tabular}

\section{CONCLUSIONS.}

The conclusions which can be drawn from the present work do not in any way alter the views expressed in the previous paper on this subject, viz., that marine burrowing animals living in estuaries are in no way affected by the presence of overflowing fresh water at low tide provided they can burrow down to a depth of about 12 inches. Only the animals which live on the surface have to be capable of adapting themselves to varying conditions, as shown by Pantin (1931).

The effect of the rate of flow of the surface water is not quite clear. In general, the faster the water runs the more quickly it appears to leach out the salt from the sand. However, the slope-factor also interferes because faster flowing streams will occur on steeper beaches, while the 
greater direct drainage through the sand in the steeper beaches will remove some of the salt water and allow its place to be taken by the overflowing fresh water.

The Whitesand Bay example shows very clearly that tidal effects are such that a very short time under the tide will bring the water in the sand back to a state of high salinity. It therefore appears to be more difficult to reduce the salinity of the water in the sand than to increase it.

I have great pleasure in recording my thanks to Mr. W. H. Barrett of Harrow School for the help he has given me in this work.

\section{BIBLIOGRAPHY.}

Pantin, C. F. A. (1931.) The Adaptation of Gunda ulve to Salinity. 1. The Environment. Journ. Exper. Biol., 8, p. 63.

ReID, D. M. (1930.) Salinity Interchange between Sea-Water in Sand and Overflowing Freshwater at Low Tide. Journ. Mar. Biol. Assoc., N.S., 16, p. 609. 